\title{
Monitoring Parking Space Availability via Zigbee Technology
}

\author{
Hee Chien Yee and Yusnita Rahayu, Senior Member, IACSIT
}

\begin{abstract}
With the rapid growth of vehicle availability and usage on the road in recent years, finding a vacant car parking space is becoming more and more difficult which resulting in a number of conflicts such as traffic problems. In this paper, a prototype of Monitoring Parking Space Vacancy System is introduced using wireless technologies to alleviate the traffic problems. The system includes two modules, parking lot vacancy monitoring module, and master module. Parking lot vacancy monitoring module consists of digital infrared sensor, liquid crystal display (LCD), and Zigbee module which are interfaced with PIC microcontroller. Master modules include laptop GUI display, and Zigbee modules. The user can get the status of parking lot vacancy through the LCD of monitoring parking vacancy module. The Zigbee transceiver on monitoring parking vacancy module which interfaced with microcontroller is to transmit the infrared sensor data when the digital infrared sensor detects the presence of vehicle in the parking areas and thus provide the status of the parking lot to be displayed in master module with Graphical User interface (GUI).
\end{abstract}

Index Terms-Parking monitoring, Zigbee, graphical user interface (GUI).

\section{INTRODUCTION}

Recent years there has been a growing credit of the importance of parking issues in the urban area parking lots [1]. With the fast pace development of national economy and living standards, the automotive industry and population is becoming more and more demanding [2]. This is thus leads to the rapid growth of vehicles in recent years. Therefore, finding a vacant car parking space becoming daily concern for most drivers and it is time consuming. For instance, a survey [3] shows that during rushing hours in big cities, the traffic generated by cars searching for parking lot vacancy takes up to $40 \%$ of total traffic. In other word, with the increasing of vehicle population in Malaysia, the demands of parking spaces in large areas are increasing too.

Finding a vacant space in a multilevel parking lot is difficult, especially on weekends or public holidays. A study showed that finding spaces during weekends or public holidays can take more than 10 minutes for about $66 \%$ of visitors. Stadiums or shopping malls are crowded at peak periods, and difficulties in finding vacant slots at these

Manuscript received March 19, 2014; revised May 28, 2014. This work was supported by Universiti Malaysia Pahang under Grant No. RDU110315.

H. C. Yee was with Universiti Malaysia Pahang (e-mail: xinerhee_90@ hotmail.com).

Yusnita Rahayu is with Faculty of Electrical and Electronics Engineering, Universiti Malaysia Pahang, Malaysia and she is also a lecturer at Electrical Engineering Department of Riau University, Indonesia (e-mail: vannebula2001@yahoo.com). places are major problem for customers [4]. Therefore, insufficient car park spaces lead to traffic congestion and driver frustration [5].

Recently in Malaysia, there are various methods used in parking lot to detect the presence of car as in [6], the authors proposed a Secure Parking Reservation System where GSM technology is used to send the data-base password to those drivers enquiry for a reservation of parking lot. The password is needed in order for the drivers to enter and exit the parking lot. Other than that, image processing technique is applied in parking to detect the presence of vehicles rather than using sensor [7]. This algorithm works in acquire the image of parking lot and calculate the occupancy of the vehicles pixel area and thus provide an accurate number of available parking lot to the users [7], [8]. Moreover, ultrasonic sensor is used in Smart Parking System(SPS) [9] to detect the presence of vehicles in parking lot and shows a green LED if there is no vehicles detected and red if there is occupancy of vehicles in that certain parking lot. The LED is installed at the top of every parking lot.

In foreign country, more techniques are applied in parking lot detection of vehicles, one of is Zigbee and GSM based secure vehicle parking management and reservation system where reservation can be made by drivers through Zigbee [10]. Furthermore, in [10] there is also a GUI display in the access and control unit that can shows the reception of the user request for lot reservation. For this project, it is proposed so to assists drivers to search the available parking space in parking area. But at first consideration, driver should know there consist of how many empty parking space before they can make choices [11]. For this reason, a simple but efficient system is required to monitor the parking space in order to ease the drivers in finding available parking space and display in LCD which located at entrance of parking lot. The Zigbee and LCD module is interfaced with microcontroller to do the wireless data transmission to the master module and master module consist of GUI display and Zigbee module as shown in Fig. 1.

\section{WORKFLOW}

\section{A. Parking Lot Vacancy Monitoring Module}

The parking lot is provided with digital infrared sensor and is permitted to sense the parking lot continuously. Whenever it detects the presence of vehicles in parking lot, it will generate event on presence of vehicles to the microcontroller to which it is interfaced. Then, microcontroller will send the information get from digital infrared sensor to both LCD and Zigbee module. The Zigbee module transmits the status data 
to the Zigbee receiver at the master module at the entrance of parking lot. Then the status of parking lot is continuous updated in the master module. The LCD display is placed at the entrance of parking lot to display the number of available parking lot. Fig. 2 below shows the flow chart of parking lot monitoring module.

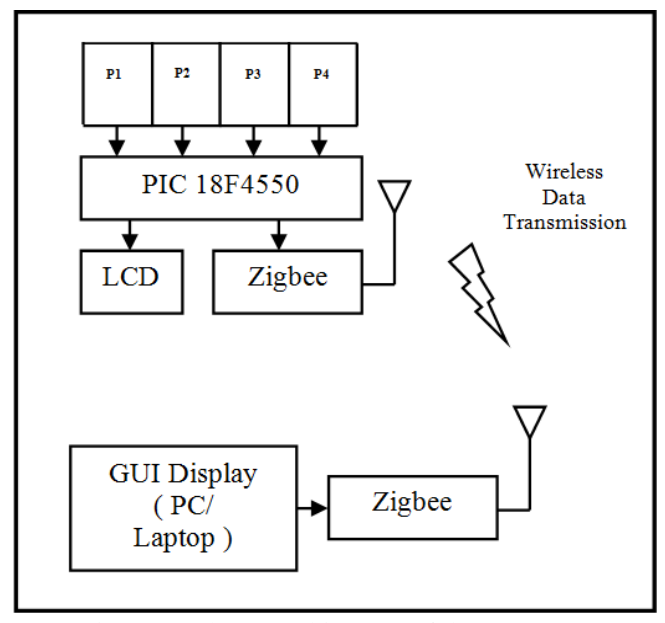

Fig. 1. Hardware architecture of the system.

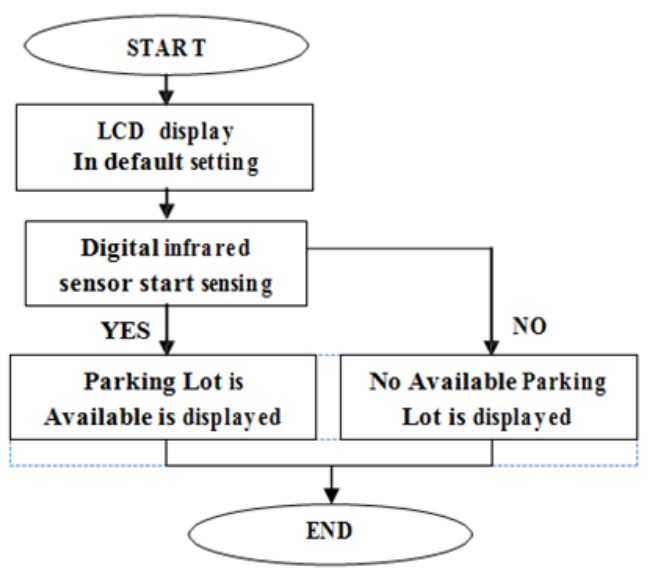

Fig. 2. Flow chart of parking lot vacancy monitoring module.

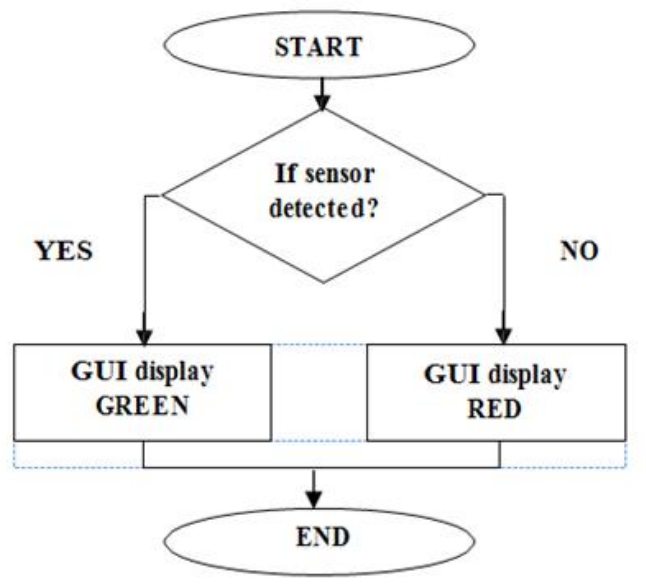

Fig. 3. Flow chart of master module.

\section{B. Master Module}

The flow chart of master module is as shown in Fig. 3. Once the system is started, the Zigbee node will receive the status information from parking lot monitoring vacancy module and master module will start to check whether there is any vacancy in parking lot and then display on the GUI displayAs said, to insert images in Word, position the cursor at the insertion point and either use Insert | Picture | From File or copy the image to the Windows clipboard and then Edit Paste Special | Picture (with "Float over text" unchecked).

The authors of the accepted manuscripts will be given a copyright form and the form should accompany your final submission.

\section{HARDARE DESIGN OVERVIEW}

The Monitoring Parking Space Vacancy System consists of sensor module, microcontroller PIC 18F4550, Zigbee module, GUI display (PC or laptop) and LCD module. Every parking lot is installed with digital infrared sensor which is function to monitor the parking area. The digital infrared sensor and Zigbee module are interfaced with microcontroller PIC 18F4550. The parking lot status is updated and transmitted continuously to the master module. There is UART communication happened between Zigbee and microcontroller. Consequently, master module will have Zigbee module interfaced with it function is to receive the transmitted parking lot status from Parking Lot Vacancy Monitoring Module.

\section{A. Microcontroller}

Microcontroller is defined as a small computer with integrated circuit containing a core processor, memory and programmable input/output peripherals. Nowadays, microcontroller is widely used in automobile engine control systems, remote controls, office machine and toys [12]. The PIC 18F4550 family introduces design enhancements that make these microcontrollers a logical choice for many high-performance applications. PIC F4550 is a good choice for this system in term of cost effectiveness and efficiency.

\section{B. Zigbee Module}

ZigBee is an energy saving communication standard designed for low-power short-range communications between wireless devices. It operates on $2.4 \mathrm{GHz}$ frequency band. The UART interface can connect directly from microcontroller to pin of Zigbee module. Using UART interface, communication between wireless devices and microcontroller can be done. Zigbee module is used to transmit the parking lot status to master module for GUI display.

\section{Sensor Module}

There is only one type of sensor used which is digital infrared sensor. Digital infrared sensor is attached on top of every parking lot to detect the existence of car. This kind of sensor can sense up to $30 \mathrm{~cm}$ distance in which the modulated IR signal immune the sensor to the interferences caused by normal light of a light bulb or the sun light.

\section{LCD Module}

LCD module is display unit interfaced with microcontroller which is placed at the entrance of parking area. The LCD module plays a role to display the status of parking lot where drivers can view the status before entering the parking lot. 


\section{RESUlT AND DISCUSSION}

The screenshot and the prototype of parking lot monitoring system are shown in the figure below. The Fig. 4 shows the circuitry board of the parking lot vacancy monitoring module.

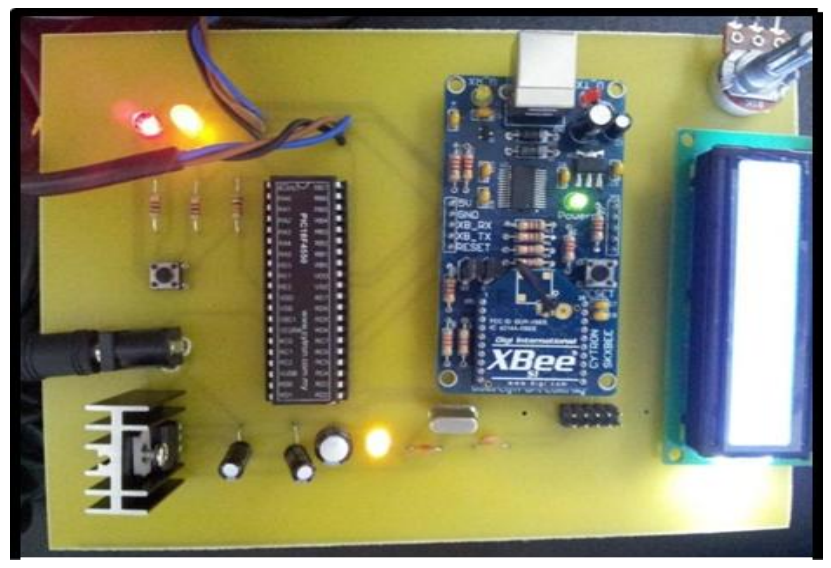

Fig. 4. Circuitry board of the parking lot vacancy monitoring module.

Fig. 5 shows the hardware prototype of parking lot vacancy monitoring module. It consists of LCD module, microcontroller PIC 18F4550, two digital infrared sensors and a Zigbee module interfaced with microcontroller.

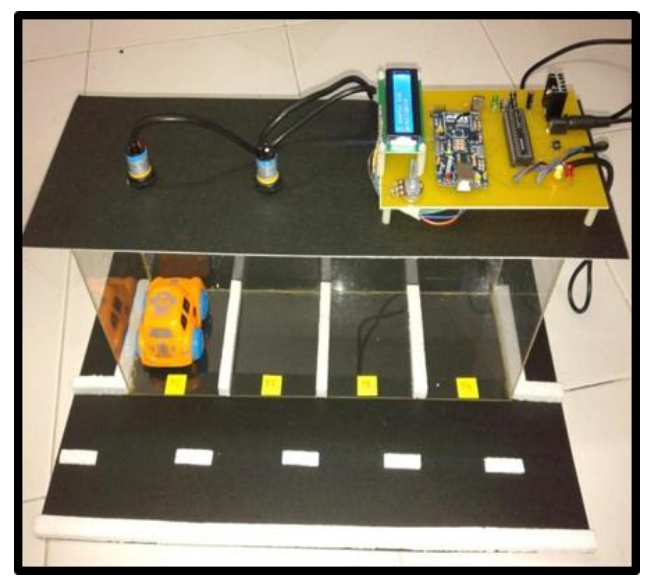

Fig. 5. Hardware prototype of parking lot vacancy monitoring module.

On the other hand, Fig. 6 shows the screenshot of GUI display in laptop. The system is constructed using Visual Studio 2008. In the GUI display, it comprises of Zigbee communication port where user need to select the COM port available in order to start the wireless data transmission between 2 Zigbees. Users need to press the start button after connecting the Zigbee COM port. The status description gives a description on which if the parking lot available it appears green and if not available, it appears red. Whereas for the parking lot area which shown 4 parking lot P1, P2, P3 and $\mathrm{P} 4$, all these button will appeared red if occupy by vehicles and appeared green if the parking lot is vacant.

In [9], ultrasonic sensor is installed to detect the presence of vehicle due to its low cost and ease of installation. Whereas, it disadvantage is the sensitivity to the temperature changes. This problem can solve by digital infrared sensor and moreover based on consideration of environment in indoor parking, the digital infrared sensor is preferable due to its waterproof, high precision and can protect from corrosion. There is all kind of infrared sensor which can sensing up to maximum $80 \mathrm{~cm}$ but digital infrared sensor is chosen here to do the modeling of the project.

Zigbee is used to implement on this project due to its low cost and low power consumption as well as its long range data integrity can sense up to $30 \mathrm{~m}$ in indoors and up to $100 \mathrm{~m}$ in outdoor. It is a new wireless data transmission technology that currently being use in many applications and various fields.

The GUI display that design in this project is to display the availability of each parking lot that put under monitor whereas as can be seen in [10], the GUI display is to shows the reception of the user request for lot reservation.

This proposed system reduces the unnecessary time used to searching empty parking spaces, and also reduces the traffic problems in parking area.

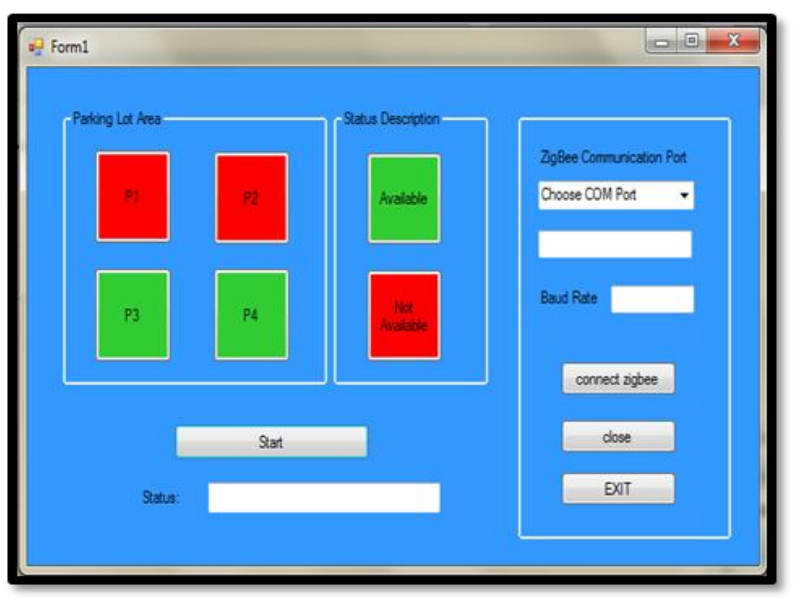

Fig. 6. GUI display.

\section{CONCLUSION}

The proposed architecture of monitoring parking space availability system can effectively satisfied the basic requirement of a driver on parking system. The sensor technology is done by using digital infrared sensor play its role in sensing the presence of vehicles. The wireless technology as well successfully transmits the parking lot status data wirelessly from parking lot vacancy monitoring module to master module. Furthermore, the GUI display can monitor the parking space continuously and the status of parking lot is updated in real time. Therefore, this proposed system can overcome the traffic congestion in finding available parking vacancy. At the same time, it offers time savings and reliability which convince the users all time. The advantages consists of less time spend and fuel consumptions while finding for parking space. Thus, this system can eliminate congestion, air pollution due to car exhaust and queues entering car park.

\section{ACKNOWLEDGMENT}

The authors like to thank for the supports from Universiti Malaysia Pahang under the project RDU 110315, and Research and innovation Department of Universiti Malaysia Pahang for helping in this project and providing financial 
support

\section{REFERENCES}

[1] K. Axhausen and J. Polak, "Choosing the type of parking: stated preference experiments in the UK and Germany," Working Paper, Transport Studies Unit, Oxford University, p. 253, 1990.

[2] N. Yong, C. Chen, X. Zhen, and W. Fang, Design of Parking Control System Based on Wireless Sensor Network, Trans Tech Publication, vol. 117-119, p. 1, 2012.

[3] P. White, No Vacancy: Park Slopes Parking Problem And How to Fix It. Transalt.org, 2007.

[4] D. B. L. Bong, K .C. Ting, and K. C. Lai, "Integrated approach in the design of car park occupancy information system (COINS)," IAENG International Journal of Computer Science, vol. 35, no. 1, 2008.

[5] M. Y. I. Idris, E. M. Tamil, N. M. Noor, and K. W. Fong, "Parking guidance system utilizing wireless sensor network and ultrasonic sensor," Information Technology Journal, vol. 8, pp. 138-146, 2009.

[6] R. Yusnita and N. Fariza, "A secure parking reservation system using GSM technology," International Journal of Computer and Communication Engineering, vol. 2, no. 4, July 2013.

[7] R. Yusnita, N. Fariza, and B. Norazawinati, "Intelligent parking space detection system based on image processing," International Journal of Innovation, Management and Technology, vol. 3, no. 3, June 2012.

[8] S. Funck, N. Mohler, and W. Oertel, "Determining car- park occupancy from single images," in Proc. the IEEE Intelligent Vehicles Symposium University of Parma, Italy, June 2004, pp. 14-17.

[9] K. Amin, M. Norli, L. Pakapan, and K. Pantea, "Smart parking system (SPS) architecture using ultrasonic detector," International Journal of Software, Engineering and Its Applications, vol. 6, no. 3, 2012.

[10] A. Sayeeraman and P. S. Ramesh, "Zigbee and GSM based secure vehicle parking management and reservation system," Journal of Theoretical and Applied Information Technology, vol. 37, no. 2, 2012.

[11] M. R. M. Kassim, "Design, development and implementation of smart home system using RF and power line communication" in Proc. $2^{\text {nd }}$ National Intelligent Systems and Information Technology Symposium (ISITS'07), vol. 3, no. 3, pp. 200-208, 1986.

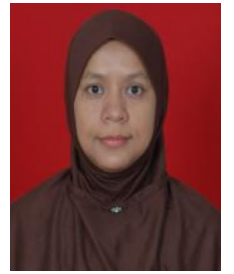

Yusnita Rahayu was born in Pekanbaru, Indonesia, November 4, 1975. She was graduated with bachelor of engineering (B.Eng) in telecommunication field from Institute Science and Technology National (ISTN), Jakarta, Indonesia in 1999, and finished her master of engineering (M.Eng) and doctor of philosophy $(\mathrm{PhD})$ in wireless communication area from Universiti Teknologi Malaysia (UTM), Johor Bahru, Malaysia in 2003 and 2008, respectively.

Currently, she is a senior lecturer and a researcher at Faculty of Electrical and Electronics Engineering of Universiti Malaysia Pahang (UMP), Malaysia. She is also lecturer at Electrical Department of Riau University, Indonesia. During her M.Eng study, she was also actively involved with some research projects under Wireless Communication Centre (WCC) of Universiti Teknologi Malaysia that were relating to wireless communication system. She has published more than 30 papers for referred national and international conference, 5 book chapters, 5 referred invited journals. Now, she is a Project Leader for the current short term project grant under Universiti Malaysia Pahang.

She is also active as a reviewer and technical program committee for various journals and conferences. She is a senior member of IEEE, member of IEEE antenna \& propagation society. Her interest areas include radio transceiver design, antenna for wireless communication application, sensor network, control, solar and monitoring system.

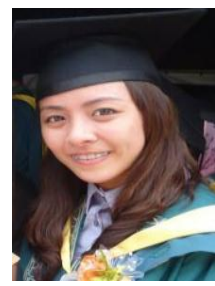

Hee Chien Yee was born in Johor Province, Malaysia, in 1990. She received the B.Eng degree (First Class) from the Universiti Malaysia Pahang in 2013 in electrical engineering. She won bronze medal during Citrex2013 for this project competition. 